\title{
Residual activity of cetrimide and chlorhexidine on Enterococcus faecalis-infected root canals
}

\author{
Carmen María Ferrer-Luque ${ }^{1}$, María Teresa Arias-Moliz ${ }^{2}$, Matilde Ruíz-Linares ${ }^{1}$, María Elena Martínez García $^{1}$ \\ and Pilar Baca ${ }^{1}$
}

Effective final irrigation regimen is an important step in order to achieve better disinfection and ensure residual antimicrobial effects after root canal preparation. The aim of this study was to compare the residual antimicrobial activity of $0.2 \%$ cetrimide, and $0.2 \%$ and $2 \%$ chlorhexidine in root canals infected with Enterococcus faecalis. Biofilms of $E$. faecalis were grown on uniradicular roots for 4 weeks. After root canal preparation, root canals were irrigated with $17 \%$ ethylenediaminetetraacetic acid (EDTA) to remove the smear layer. The roots were randomly divided into three experimental groups $(n=26)$ according to the final irrigating solution: Group I, $5 \mathrm{~mL}$ $0.2 \%$ cetrimide; Group II, $5 \mathrm{~mL} 0.2 \%$ chlorhexidine; and Group III, $5 \mathrm{~mL} 2 \%$ chlorhexidine. Samples were collected for 50 days to denote the presence of bacterial growth. The proportion of ungrown specimens over 50 days was evaluated using the nonparametric Kaplan-Meier survival analysis. Differences among groups were tested using the log-rank test and the level of statistical significance was set at $P<0.05$. The highest survival value was found with $2 \%$ chlorhexidine, showing statistically significant differences from the other two groups. At 50 days, E. faecalis growth was detected in $69.23 \%$ specimens in Groups I and II, and in $34.61 \%$ specimens of Group III. There were no significant differences between $0.2 \%$ cetrimide and $0.2 \%$ chlorhexidine. Final irrigation with $2 \%$ chlorhexidine showed greater residual activity than $0.2 \%$ chlorhexidine and $0.2 \%$ cetrimide in root canals infected with $E$. faecalis. International Journal of Oral Science (2013) 6, 46-49; doi:10.1038/ijos.2013.95; published 20 December 2013

Keywords: antimicrobial effects; biofilms; cetrimide; chlorhexidine; Enterococcus faecalis; final irrigation; residual activity

\section{INTRODUCTION}

The success of endodontic therapy is directly related with the control of endodontic microbiota during root canal treatment. ${ }^{1}$ Sodium hypochlorite $(\mathrm{NaOCl})$ is the main irrigating solution used in root canal preparation to dissolve vital and necrotic tissue and eliminate the bacteria of instrumented root canals, ${ }^{2-3}$ but it lacks residual antimicrobial activity. ${ }^{4}$ Chelating agents are used to remove debris and smear layer from instrumented root canals; ${ }^{5-6}$ their residual activity on root canals infected with Enterococcus faecalis has been demonstrated. ${ }^{7}$

Chlorhexidine, a potent antiseptic agent, is recommended as a final irrigating solution in view of its antimicrobial action, ${ }^{8}$ proven substantivity ${ }^{9}$ and capacity to inhibit the adherence of certain bacteria to dentin. ${ }^{10}$ Cetrimide is a cationic surfactant with bactericidal activity ${ }^{11}$ and the capacity to decrease the biofilm's mechanical stability. ${ }^{12}$ Solutions of $2 \%$ chlorhexidine and $0.2 \%$ cetrimide, when applied for $1 \mathrm{~min}$ alone or in final irrigation protocols, can completely inhibit the 24-h E. faecalis biofilm formation in dentin, ${ }^{13}$ while the combination of $2 \%$ chlorhexidine $+0.2 \%$ cetrimide after the use of chelating agents ${ }^{14}$ has been proposed as an effective alternative for final irrigation in root canals because of its antimicrobial action over time.

It was recently shown that $0.2 \%$ cetrimide provides longer substantivity than $0.2 \%$ chlorhexidine and nearly as long as that of $2 \%$ chlorhexidine in a dentin-volumetric model. ${ }^{15}$ Nonetheless, there are no data about its antimicrobial activity and ability over time to control bacterial regrowth when used alone as the final irrigating solution after root canal preparation. The aim of this study was therefore to compare the residual antimicrobial activity of $0.2 \%$ cetrimide with $0.2 \%$ and $2 \%$ chlorhexidine in root canals infected with E. faecalis.

\section{MATERIALS AND METHODS}

Eighty-six anterior human teeth stored in $0.1 \%$ thymol solution at $4{ }^{\circ} \mathrm{C}$ were decoronated to obtain roots $12 \mathrm{~mm}$ in length. This study was conducted using a protocol previously approved by the Ethics Committee of the University of Granada. A customized model of each tooth was made. ${ }^{14}$ Each root and its corresponding model were autoclaved at $121{ }^{\circ} \mathrm{C}$. After sterilization, the specimens were incubated in brain heart infusion (BHI) broth (Scharlau Chemie S.A., Barcelona, Spain) for $24 \mathrm{~h}$ at $37{ }^{\circ} \mathrm{C}$ to ensure no bacterial contamination.

From a subculture of E. faecalis (ATCC 29212), a standard suspension was prepared in $\mathrm{BHI}$ to obtain $1 \times 10^{7}$ colony-forming units (CFU) per mL. Afterwards, $1.2 \mathrm{~mL}$ of this suspension and the sterilized tooth were added to an Eppendorf tube and were incubated for 4 weeks under aerobic conditions at $37{ }^{\circ} \mathrm{C}$, with re-inoculation performed every seven days. The cultures were checked for purity by Gram stain and colony

${ }^{1}$ Department of Stomatology, School of Dentistry, University of Granada, Granada, Spain and ${ }^{2}$ Department of Microbiology, School of Dentistry, University of Granada, Granada, Spain

Correspondence: Dr CM Ferrer-Luque, Department of Stomatology, School of Dentistry, University of Granada, Campus de Cartuja, Colegio Máximo s/n, Granada E-18071, Spain E-mail: cferrer@ugr.es

Accepted 11 November 2013 
Table 1 Number and percentage of regrown specimens

\begin{tabular}{|c|c|c|c|c|c|}
\hline Irrigating solution & $\begin{array}{c}\text { Number (percentage) of } \\
\text { regrown samples }\end{array}$ & Minimum & Maximum & Median & Mean \pm standard deviation \\
\hline Group I: $0.2 \%$ cetrimide $^{a}$ & $18(69.23 \%)$ & 4 & $>50$ & 27 & $29.92 \pm 14.73$ \\
\hline Group II: $0.2 \%$ chlorhexidine ${ }^{a}$ & $18(69.23 \%)$ & 4 & $>50$ & 28 & $31.80 \pm 13.66$ \\
\hline
\end{tabular}

The same superscript letter shows differences that were not statistically significant, determined by the log-rank test $(P<0.05)$.

$n=26$, per group.

morphology, and two samples were processed to confirm the presence of E. faecalis biofilm by scanning electron microscopy.

The working length was established for each tooth by introducing a \#10 K-file (Dentsply Maillefer, Ballaigues, Switzerland) into the canal until it was observed at the apical foramen, then decreasing the file length by $1 \mathrm{~mm}$. The apexes of the teeth were sealed with cyanoacrylate. Each tooth was then inserted into its customized model and the interface was sealed with cyanoacrylate. The root canals were instrumented using the ProTaper system to working length using a F3 master apical file (Dentsply Maillefer, Ballaigues, Switzerland), following the manufacturers' instructions. During preparation, $1 \mathrm{~mL}$ of $5.25 \%$ $\mathrm{NaOCl}$ was applied after each file.

Once instrumented, the roots were irrigated with $5 \mathrm{~mL} \mathrm{17 \%}$ ethylenediaminetetraacetic acid (EDTA) solution to remove the smear layer. The roots were then randomly divided into three experimental groups $(n=26)$ according to the final irrigating solution: Group I, $5 \mathrm{~mL}$

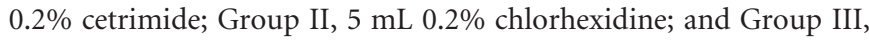
$5 \mathrm{~mL} 2 \%$ chlorhexidine. All the irrigating solutions were delivered for one minute through a $3 \mathrm{~mL}$ Luer-Loc syringe coupled to an open-end 30 -gauge needle tip. In each group, two other specimens $(n=6)$ not contaminated with $E$. faecalis received the same treatment and served as negative controls.

After preparation, the root canals were dried with sterile paper points (Dentsply Maillefer, Ballaigues, Switzerland) and filled with BHI broth. A \#15 K-file (Dentsply Maillefer, Ballaigues, Switzerland) was placed in the canal to working length and the canal was circumferentially filed for $10 \mathrm{~s}$. Three consecutive sterile paper points were introduced into the canal to absorb the BHI broth. The paper points were transferred to an Eppendorf tube containing $5 \mathrm{~mL}$ of BHI broth. After collection of the first bacterial sample, the canal was refilled with the same broth and samples were collected daily for 50 days. All collected samples were incubated $24 \mathrm{~h}$ at $37{ }^{\circ} \mathrm{C}$. Turbidity was recorded for each specimen as an indicator of bacterial growth. Once turbidity was present, bacteria were identified to ensure that there was no contamination other than E. faecalis.

The proportion of ungrown specimens over 50 days was evaluated using nonparametric Kaplan-Meier survival analysis. Differences among groups were tested using the log-rank test and the level of statistical significance was set at $P<0.05$. All statistical analyses were performed by means of SPSS 17.0 software (SPSS, Chicago IL, USA).

\section{RESULTS}

Table 1 shows the number of regrown samples and the median and mean \pm standard deviation of the day of regrowth. At 50 days, E. faecalis growth was detected in $69.23 \%$ specimens in Groups I and II, and in $34.61 \%$ specimens in the $2 \%$ chlorhexidine group. The results of Kaplan-Meier survival analysis are shown in Figure 1. The highest survival value was with $2 \%$ chlorhexidine. Pair comparisons determined by the log-rank test showed statistically significant differences between $2 \%$ chlorhexidine and the other groups. There were

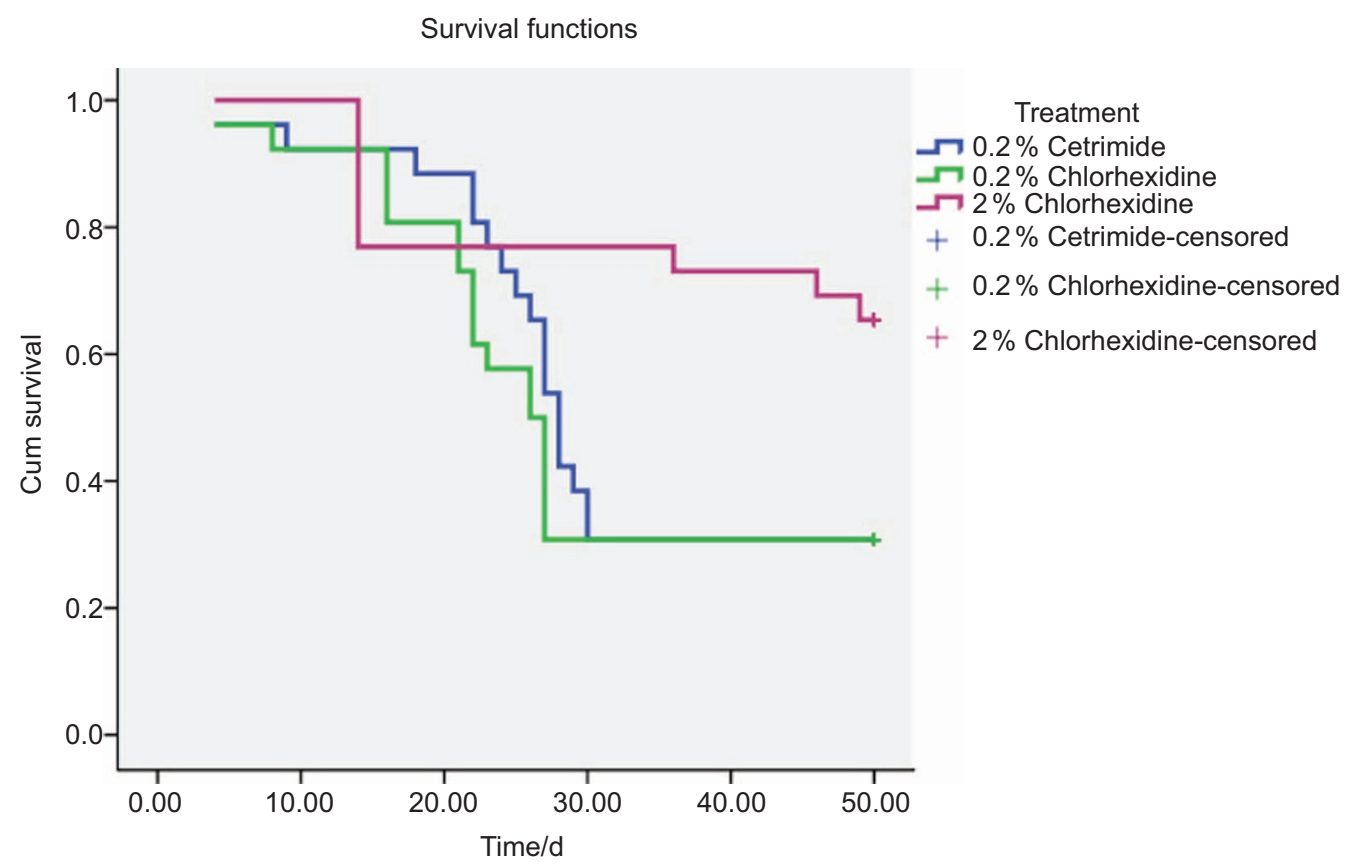

Figure 1 Kaplan-Meier survival probabilities at $\mathbf{5 0}$ days (probability of no regrowth) for all groups. Censored represents the proportion of the samples showing no regrowth at the end of the time period. Cum survival is the percentage of samples that did not show E. faecalis regrowth at a given time. 
no significant differences between groups $0.2 \%$ cetrimide and $0.2 \%$ chlorhexidine.

\section{DISCUSSION}

Failure of root canal treatment may occur from viable residual bacteria present within the root canal systems. ${ }^{16-17}$ The high prevalence of $E$. faecalis in teeth with post-treatment disease is due to its ability to compete with other microorganisms, invade dentinal tubules, resist nutritional deprivation and grow as a biofilm on root canal walls. ${ }^{18}$

The aim of this study was to compare over time the residual activity of $0.2 \%$ cetrimide, $0.2 \%$ chlorhexidine and $2 \%$ chlorhexidine in root canals infected with E. faecalis. The strain used was E. faecalis ATCC 29212, a strain of reference widely used in antimicrobial susceptibility studies $^{7,11,13-15}$ allowing the comparison of results. The application time was $1 \mathrm{~min}$, as recommended to kill E. faecalis ${ }^{11,19}$ and achieve residual antibacterial activity with these agents. ${ }^{10}$ A $17 \%$ EDTA solution was used to remove the smear layer, to prevent the formation of a precipitate associated with chlorhexidine and $\mathrm{NaOCl}$ interaction ${ }^{20-21}$ and to promote substantivity over time of chlorhexidine in the presence of collagen. ${ }^{15,22}$

The antimicrobial activity of chlorhexidine depends on the number of molecules available to interact with the dentin. ${ }^{8}$ Accordingly, a more concentrated chlorhexidine preparation should result in increased resistance to microbial regrowth. Residual effects of $2 \%$ chlorhexidine and $0.12 \%$ chlorhexidine have been reported in root canal irrigation evaluated ex vivo ${ }^{23}$ and in $v i v o^{24}$ in short time periods. In the present study, all solutions tested showed residual effects in some specimens for over 50 days when used as final irrigating solutions in infected root canals (Figure 1). As expected, the residual activity was directly related to the concentration of the chlorhexidine solution. The higher concentration tested (2\%) showed a greater capacity to inhibit E. faecalis regrowth: at 50 days, only 9/26 specimens showed regrowth. There were significant differences with respect to $0.2 \%$ chlorhexidine as well as $0.2 \%$ cetrimide (both $18 / 26$ ) (Table 1 ). It is noteworthy that regrowth in the $2 \%$ chlorhexidine group did not occur in any specimen until day 14 - similar to results obtained with a combined solution of $2 \%$ chlorhexidine $+0.2 \%$ cetrimide using the same methodology. ${ }^{14}$

Nearly identical results were obtained in Groups I and II: in both, the first regrowth occurred on the fourth day and at 50 days, regrowth was seen in 18 samples (Table 1 ).

Although $0.2 \%$ cetrimide showed a high residual activity (median: 27 days), a result closer to the one obtained with $2 \%$ chlorhexidine had been anticipated, given its greater ability to kill E. faecalis ${ }^{11}$ and comparable substantivity determined in a volumetric-dentin unit. ${ }^{15}$ This type of sample provides for optimal controlled conditions on the entire surface, allowing mechanical trapping of the solution inside the open dentinal tubules and binding to the exposed collagen matrix. The present study involved the use of roots where the low surface tension of cetrimide facilitated its diffusion in the main root canal, but the penetration of the solutions into dentinal tubules may be compromised. ${ }^{25-26}$ However, it has been shown that the addition of cetrimide in the disinfecting solutions increased their antibacterial effects against E. faecalis in the dentinal tubules. ${ }^{27}$ In this sense, the results obtained in this study suggest that the antibacterial residual effect of cetrimide would depend on its concentration and the length of its application time, ${ }^{11}$ or its association with antiseptic agents. ${ }^{14,27-28}$

Recently, $1 \%$ of alexidine, a bisbiguanide disinfectant, has shown similar antibacterial effect to $2 \%$ chlorhexidine against $E$. faecalis in bovine dentin. ${ }^{29}$ Further studies are needed to determine the best solution and/or combination of solutions, in the irrigation regime or as supplementary approach, ${ }^{29-30}$ to not only disinfect but also maintain a significant residual antimicrobial activity over time. In conclusion, under the limitations of the present study, final irrigation with $0.2 \%$ cetrimide and $0.2 \%$ chlorhexidine showed lower residual activity than $2 \%$ chlorhexidine in root canals infected with E. faecalis.

\section{ACKNOWLEDGEMENTS}

The authors thank Francisca Castillo Pérez for her technical assistance. This study was supported by the Research Group CTS-167 of the Junta de Andalucía, Spain.

1 Siqueira JF Jr, Lima KC, Magalhães FA et al. Mechanical reduction of the bacterial population in the root canal by three instrumentation techniques. J Endod 1999; 25(5): 332-335.

2 Bystrom A, Sundqvist $G$. The antibacterial action of sodium hypochlorite and EDTA in 60 cases of endodontic therapy. Int Endod J 1985; 18(1): 35-40.

3 Siqueira JF Jr, Rôças IN, Santos SR et al. Efficacy of instrumentation techniques and irrigation regimens in reducing the bacterial population within root canals. $J$ Endod 2002; 28(3): 181-184.

4 Weber CD, McClanahan SB, Miller GA et al. The effect of passive ultrasonic activation of $2 \%$ chlorhexidine or $5.25 \%$ sodium hypochlorite irrigant on residual antimicrobial activity in root canals. J Endod 2003; 29(9): 562-564.

5 Pérez-Heredia M, Ferrer-Luque CM, González-Rodríguez MP. The effectiveness of different acid irrigating solutions in root canal cleaning after hand and rotary instrumentation. J Endod 2006; 32(10): 993-997.

6 Ballal NV, Kandian S, Mala K et al. Comparison of the efficacy of maleic acid and ethylenediaminetetraacetic acid in smear layer removal from instrumented human root canal: a scanning electron microscopic study. J Endod 2009; 35(11): 1573-1576.

7 Ferrer-Luque CM, Conde-Ortiz A, Arias-Moliz MT et al. Residual activity of chelating agents and their combinations with cetrimide on root canals infected with Enterococcus faecalis. J Endod 2012; 38(6): 826-828.

8 Mohammadi Z, Abbott PV. The properties and applications of chlorhexidine in endodontics. Int Endod J 2009; 42(4): 288-302.

9 Mohammadi Z, Abbott PV. Antimicrobial substantivity of root canal irrigants and medicaments: a review. Aust Endod J 2009; 35(3): 131-139.

10 Kishen A, Sum CP, Mathew $S$ et al. Influence of irrigation regimens on the adherence of Enterococcus faecalis to root canal dentin. J Endod 2008; 34(7): 850-854.

11 Arias-Moliz MT, Ferrer-Luque CM, González-Rodríguez MP et al. Eradication of Enterococcus faecalis biofilms by cetrimide and chlorhexidine. J Endod 2010; 36(1): 87-90.

12 Simoes M, Pereira MO, Vieira MJ. Effect of mechanical stress on biofilms challenged by different chemicals. Water Res 2005; 39(20): 5142-5152.

13 Baca P, Junco P, Arias-Moliz MT et al. Residual and antimicrobial activity of final irrigation protocols on Enterococcus faecalis biofilm in dentin. J Endod 2011; 37(3): 363-366.

14 Baca P, Mendoza-Llamas ML, Arias-Moliz MT et al. Residual effectiveness of final irrigation regimens on Enteroccus faecalis-infected root canals. J Endod 2011;37(8): 1121-1123.

15 Baca P, Junco P, Arias-Moliz MT et al. Antimicrobial substantivity over time of chlorhexidine and cetrimide. J Endod 2012; 38(7): 927-930.

16 Safavi KE, Spangberg LS, Langeland K. Root canal dentinal tubule disinfection. $J$ Endod 1990; 16(5): 207-210.

17 Buck RA, Eleazer PD, Staat RH et al. Effectiveness of three endodontic irrigants at various tubular depths in human dentin. J Endod 2001; 27(3): 206-208.

18 Distel JW, Hatton JF, Gillespie MJ. Biofilm formation in medicated root canals. J Endod 2002; 28(10): 689-693.

19 Gomes BP, Ferraz CC, Ferraz CC et al. In vitro antimicrobial activity of several concentrations of sodium hypochlorite and chlorhexidine gluconate in the elimination of Enterococcus faecalis. Int Endod J 2001; 34(6): 424-428.

20 Marchesan MA, Pasternak Júnior B, Afonso MM et al. Chemical analysis of the flocculate formed by the association of sodium hypochlorite and chlorhexidine. Oral Surg Oral Med Oral Pathol Oral Radiol Endod 2007; 103(5): e103-e105.

21 Rossi-Fedele G, Doğramaci EJ, Guastalli AR et al. Antagonistic interactions between sodium hypochlorite, chlorhexidine, EDTA, and citric acid. J Endod 2012; 38(4): 426-431.

$22 \mathrm{Kim}$ J, Uchiyama T, Carrilho $\mathrm{M}$ et al. Chlorhexidine binding to mineralized versus demineralized dentin powder. Dent Mater 2010; 26(8): 771-778.

23 White RR, Hays GL, Janer LR. Residual antimicrobial activity after canal irrigation with chlorhexidine. J Endod 1997; 23(4): 229-231.

24 Leonardo MR, Tanomaru Filho M, Silva LA et al. In vivo antimicrobial activity of $2 \%$ chlorhexidine used as a root canal irrigating solution. J Endod 1999; 25(3): 167-171.

25 Attal JP, Asmussen E, Degrange M. Effects of surface treatment on the free surface energy of dentin. Dent Mater 1994; 10(4): 259-264.

26 Portenier I, Haapasalo H, Orstavik D et al. Inactivation of the antibacterial activity of iodine potassium iodide and chlorhexidine digluconate against Enterococcus faecalis 
by dentin, dentin matrix, type-I collagen, and heat-killed microbial whole cells. J Endod 2002; 28(9): 634-637.

27 Wang Z, Shen Y, Ma J et al. The effect of detergents on the antibacterial activity of disinfecting solutions in dentin. J Endod 2012; 38(7): 948-953.

28 Portenier I, Waltimo T, Ørstavik D et al. Killing of Enterococcus faecalis by MTAD and chlorhexidine digluconate with or without cetrimide in the presence or absence of dentine powder or BSA. J Endod 2006; 32(2): 138-141.

29 Kim HS, Woo Chang S, Baek SH et al. Antimicrobial effect of alexidine and chlorhexidine against Enterococcus faecalis infection. Int J Oral Sci 2013; 5(1): 26-31.
30 Alves FR, Almeida BM, Neves MA et al. Disinfecting oval-shaped root canals: effectiveness of different supplementary approaches. J Endod 2011; 37(4): 496501.

(c) This work is licensed under a Creative Commons

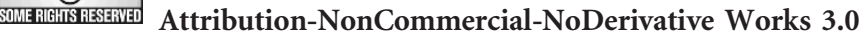
Unported License. To view a copy of this license, visit http:// creativecommons.org/licenses/by-nc-nd/3.0 